\title{
Characterization Microstructural of Kevlar-based Composites Obtained by Vacuum Infusion Process
}

Erika Osiris Ávila Dávila ${ }^{1}$, Edgar Vera Cárdenas ${ }^{1}$, Alma Guadalupe Camargo Muciño ${ }^{3}$, Marisa Moreno Rios $^{1}$, Saul Ledesma Ledesma ${ }^{3}$, Armando Irvin Martínez Pérez ${ }^{4}$ and Nicolas Cayetano Castro ${ }^{5}$

${ }^{1}$ TecNM/Instituto Tecnológico de Pachuca, Pachuca, Hidalgo, Mexico, ${ }^{3}$ Instituto Tecnologico de Pachuca, Pachuca, Hidalgo, Mexico, ${ }^{3}$ Centro de Ingenieria y Desarrollo Industrial, Queretaro, Queretaro de Arteaga, Mexico, ${ }^{4}$ Universidad Politécnica de Pachuca, Zempoala, Hidalgo, Mexico, ${ }^{5}$ Instituto Politecnico Nacional, Ciudad de Mexico, Distrito Federal, Mexico

Composite materials are widely used as structural engineering materials due to their good mechanical strength and stiffness [1]. These materials have low values of density. Thus, their applications are especially important as components of airplanes, ships, spacecraft, robots, prostheses and automobiles [2]. Particularly, fiber reinforced composite materials are an excellent example of highly strength and stiffness composites [2]. Moreover, the fiber and matrix types used in the composite fabrication are clearly important parameters to obtain high values of mechanical properties. Also, depending on the manufacturing process it is possible to achieve that the values of macroscopic properties in the composite can be close to these ideal properties of the material in a microscopic scale. A longer size of the composite material increases the possibility of generating imperfections or impurities that modify the characteristics of the bulk material [2], which inherently will affect the values of mechanical strength and stiffness of the material. The arrangement of fibers in the composite material can be aligned in one or more directions to promote selective reinforcement in the material. In this study the diameter of the fibers used is of about $1 \times 10^{-6} \mathrm{~m}$ and their arrangement is bi-directional. The types of fibers used in this investigation to fabricate the composites were Glass, Carbon and Kevlar. It is important to mention that due to the small diameter of the fibers, the manufacture of the composite consisted of bi-directional arrangements, at $90^{\circ}$, of fiber groups. The matrix of the composites used in this study was epoxy resin, which, in curing conditions, at $30{ }^{\circ} \mathrm{C}$ of temperature for 24 hours, has a value of tensile strength $\sim 51 \mathrm{MPa}$ and a value of elongation $\sim 4.5$ $\%$ [3]. Thus, it is expected that fibers reinforcing a polymer matrix of epoxy resin increase the values of mechanical properties mentioned above. There are different manufacturing processes for these materials, such as: laminated by hand and cured according to manufacturer instruction under vacuum; hand layup technique followed by compression molding process; hand lay-up method on a flat glass sheet and impregnation of the layers on each other by the epoxy resin where the laminate is covered by another glass sheet, and is set under a pressure [4-6]. In each one of these processes it is common the occurrence of air inclusions. This work used the manufacturing technique of vacuum infusion process (VIP). So, it is expected this technique shows a minimum quantity of air inclusions. The three composites materials used consisted in an outer layer of Kevlar sheet followed by the conventional core of the composite material with Glass, Carbon and Kevlar fibers, respectively. To clarify the effect of the manufacture process on the structural integrity of each composite, an analysis of each specimen was carried out by optical microscopy $(\mathrm{OM})$ with an Axiobserver D1m-Carl Zeiss, and by high resolution scanning electron microscopy (HRSEM) with a JEOL JSM-7800F equipped with EDX analysis at $20 \mathrm{kV}$. The efficiency of the VIP process was confirmed and were obtained highly homogeneous composite materials, Figure 1(a-f). Some differences as delamination in the Kevlar composite, indicated by circles in Figure 1(c,e), were also identified [7]. 


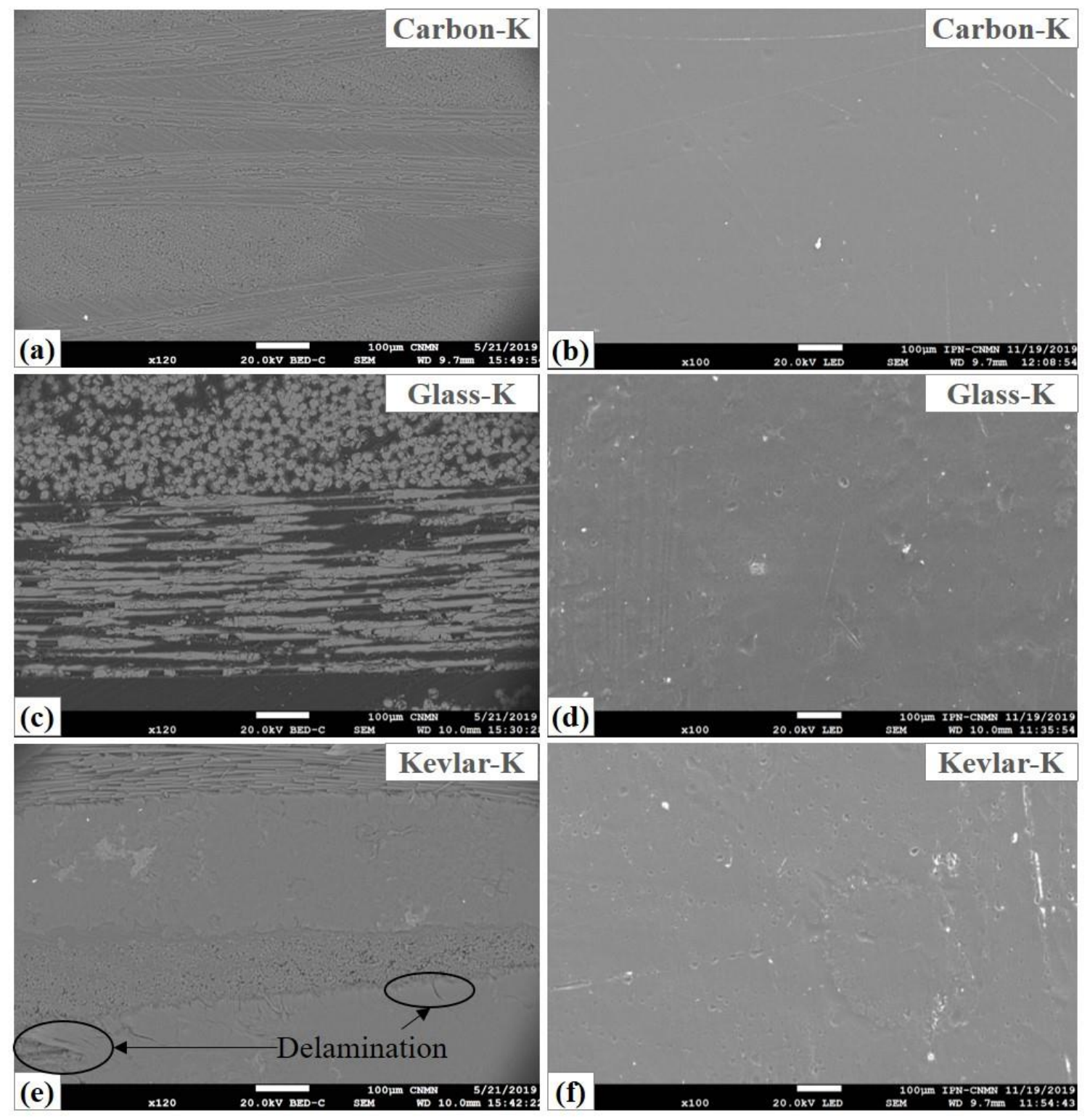

Figure 1. Micrographs of composites obtained by HR-SEM: (a-b) Carbon-K, (c-d) Glass-K, and (e-f) Kevlar-K. Cross section and surface, respectively.

\section{References}

[1] A Leif, F Donald and R Byron, Experimetal Characterization of Advanced Composite Materials, 4th ed. (CRC Press, Taylor \& Francis Group, New York, USA) p. 1-62.

[2] W Michael, Stress Analysis of Fiber-Reinforced Composite Materials, Update ed. (DEStech Publications, Inc. Pennsylvania, USA) p. 1-42.

[3] AXSON TECHNOLOGIES US, Technical data sheet, Epolam 2015 Resin.

[4] U S Tewari, A P Harsha, A M Häger, K Friedrich, Composites Science and Technology 63 (2003), p. 549-557.

[5] L Halil, K Vlastimil, et al, Composites Science and Technology 105 (2014) p. 144-150.

[6] K Sudarshan, Y S Varadarajan and N Rajendra, Materials Today: Proceedings 2 (2015) p. 2975-2983.

[7] The authors wish to acknowledge financial support from TecNM/ITPachuca. 